\title{
PERSEPSI MAHASISWA TERHADAP IFRS DAN KOMPETENSI MAHASISWA DALAM MEMAHAMI DAN MENGAPLIKASIKAN IFRS
}

\author{
Andrey Hasiholan Pulungan \\ Program Studi Akuntansi Sekolah Tinggi Ilmu Ekonomi Prasetiya Mulya
}

\begin{abstract}
Globalization, ASEAN Free Trade started in 2015, and IFRS implementation in Indonesia require universities to produce competent accounting graduates, specifically in IFRS. The purpose of this research is to analyze students' perceptions on IFRS and their competence in IFRS. The respondents are 81 students from three private universities in Jakarta, Banten, and West Java. The students must be taking or must have taken Advance Accounting subject. The results show that students realize that IFRS is important for working as accountant and IFRS has been also integrated in their learning process in campus. However, students perceive that they do not have good competency in understanding applying IFRS. Most respondents state that they are difficult to learn IFRS due to unclear explanation from lecturer, text book in English, and lack of facilities to learn IFRS.
\end{abstract}

Key Words: IFRS, Competency, and Students' Perceptions.

\section{Pendahuluan}

Globalisasi, perkembangan teknologi yang pesat, dan penerapan IFRS menuntut para lulusan akuntansi yang kompeten. Akuntan diharapkan yang memiliki kemampuan teknis, seperti menguasai IFRS atau PSAK berbasis IFRS, maupun non-teknis, seperti berpikir kritis. Akuntan harus berperan dalam pembangunan sektor publik dan swasta Ikatan Akuntan Indonesia (IAI, 2013a).

Keikutsertaan Indonesia di dalam perdagangan bebas ASEAN di tahun 2015 sebagai bagian dari ASEAN Economic Community telah memberikan tantangan tersendiri. Negara-negara ASEAN menyetujui kerangka kerjasama pada jasa akuntansi (Mutual Recognition Arrangement Framework on Accountancy Services) sebagai bagian komunitas ekonomi ASEAN atau (ASEAN, 2009). Salah satu isi mutual recognition arrangement (MRA) tersebut adalah seorang akuntan profesional (practicing profesional accountant/PPA) yang telah memenuhi persyaratan yang telah ditentukan bersama, akan diberikan izin untuk bekerja secara di tiap negara ASEAN dengan mengikuti peraturan local yang berlaku. Kemendag (2012, hal.80). menyatakan bahwa Indonesia perlu meningkatkan sumber daya manusianya agar tidak kalah bersaing dengan tenaga kerja terampil dari luar. Akuntan Indonesia diharapkan dapat berkompetisi dengan akuntan dari negara ASEAN lainnya.

Akan tetapi, saat ini timbul kekhawatiran akan kemampuan akuntan Indonesia bersaing pada perdagangan bebas ASEAN. Kekhawatiran pertama terkait dengan jumlah akuntan Indonesia. Laporan ASEAN Federation Accountant (2012) menyebutkan bahwa jumlah anggota IAI adalah 12,548 orang. Jumlah tersebut lebih kecil dibandingkan dengan jumlah anggota asosiasi akuntan di Thailand (54,319), Malaysia $(29,179)$, Singapura $(25,726)$, dan Filipina (22,567). Pusat Pembinaan Akuntan dan Jasa Penilai atau PPAJP 
(dikutip oleh IAI, 2012) melaporkan bahwa pada tahun 2012, hanya ada sekitar 1.000 akuntan publik di Indonesia. Sedangkan jumlah akuntan publik di Malaysia sebanyak 2.500, Filipina 4.941, dan Thailand 6.000. Undang-Undang no 5 tahun 2011 yang memperbolehkan akuntan publik asing bekerja dan membuka kantor di Indonesia tentu menjadi jalan bagi akuntan publik asing untuk memasuki pasar di Indonesia yang besar. Apabila akuntan Indonesia yang lebih sedikit secara kuantitas juga tidak didukung dengan kualitas yang baik, maka sangat mungkin akuntan Indonesia tidak dapat bersaing dengan akuntan publik dari negara ASEAN lainnya.

Kekhawatiran yang kedua terkait dengan kemampuan akuntan Indonesia bersaing di tahun 2015 . Wakil Menteri Keuangan, Mahendra Siregar (dikutip oleh IAI, 2013), menyatakan bahwa daya saing akuntan Indonesia masih kurang dibandingkan dengan akuntan-akuntan dari negara lain karena kurangnya kesadaran akuntan Indonesia untuk memperbaharui ilmu mereka. Salah satu pengetahuan yang perlu diperbaharui oleh akuntan adalah konvergensi IFRS dalam standar akuntansi keuangan di Indonesia. Wahyuni (2012) juga menemukan bahwa sekalipun akuntan secara umum yakin bahwa Indonesia siap dengan konvergensi IFRS, akuntan publik yang tidak berafiliasi dengan asing lebih tidak siap dengan konvergensi IFRS.

Disamping akuntan, mahasiswa akutansi Indonesia juga menghadapi tantangan akan IFRS. Standar akuntansi yang masih mengalami transisi standar akuntansi keuangan dapat menyebabkan mahasiswa tingkat akhir yang belum tentu mendapatkan pengetahuan yang seharusnya mengenai standar akuntansi keuangan di Indonesia yang berkonvergensi dengan IFRS. Ketidaksiapan mahasiswa terhadap IFRS dipengaruhi juga oleh ketidaksiapan tenaga pengajar, kekurangan bahan ajar, bahasa, dan sebagainya (Widiastuti, 2012, Coetzee \& Schmulian, 2013 dan Carvalho \& Salotti, 2013).

Hal ini tentu menjadi dilema mengingat mahasiswa akuntansi saat ini akan bersaing dengan para lulusan akuntansi di ASEAN. IFRS adalah standar yang telah dikonvergensi dalam standar akuntansi keuangan negara-negara di ASEAN. Kemampuan dalam memahami IFRS akan meningkatkan daya saing mahasiswa akuntansi Indonesia.

Penelitian ini bertujuan pada mengevaluasi persepsi kesiapan mahasiswa akuntansi terhadap implementasi IFRS beserta faktorfaktor yang mendukung maupun menghambat kesiapan mereka. Tidak seperti kebanyakan responden di berbagai penelitian yang cenderung berasal dari satu institusi pendidikan, penelitian ini mengambil responden dari beberapa propinsi dan universitas di Indonesia.

\section{Tinjauan Literatur}

Sebagai negara G20, para pembuat kebijakan akuntansi di Indonesia dan negara-negara G20 lainnya diwajibkan untuk memiliki sebuah standar akuntansi yang berlaku secara global (G20 cited in IMF, 2009). Pada tahun 2012, Indonesia menerbitkan Pernyataan Standar Akuntansi Keuangan yang sebagian besar merupakan konvergensi dengan IFRS tahun 2009. Standar tersebut tetap direview agar mengikuti perkembangan IFRS.

Konvergensi IFRS tidak hanya menuntuk akuntan dan para pendidik untuk tetap memperbaharui pengetahuannya, namun juga 
mahasiswa di perguruan tinggi. yang cukup menjadi tantangan Menjelang perdagangan bebas mengingat perusahaan memandang ASEAN yang semakin dekat, lulusan bahwa mahasiswa perlu memiliki akuntansi dari perguruan tinggi di Indonesia seyogyanya dapat bersaing dengan lulusan dari negara-negara ASEAN lainnya. Memiliki pengetahuan akan IFRS adalah salah satu kualitas yang diperlukan.

Penelitian-penelitian mengenai persepsi akademisi, khsususnya mahasiswa terhadap implementasi IFRS di dalam dunia pendidikan cenderung lebih sedikit dibandingkan dengan penelitian mengenai dampak IFRS bagi perusahaan dan pasar saham. Beberapa penelitian mengenai persepsi mahasiswa terhadap IFRS dilakukan di Amerika Serikat, misalnya Chiang (2013) dan James \& Blaszcyznski (2010). Mereka menemukan bahwa sekalipun mahasiswa memandang penting mempelajari IFRS dan perlunya IFRS diintegrasikan ke dalam kurikulum akuntansi, mahasiswa tidak yakin bahwa mereka memiliki pengetahuan akan IFRS yang cukup. Ketidakyakinan mahasiswa bahwa mereka memiliki pengetahuan IFRS pengetahuan dan kemampuan dalam membandingkan IFRS dengan standar akuntansi lokal, dan membaca dan memahami laporan keuangan berbasis IFRS (Yoon, Vedd, \& Jones, 2013). Dengan menggunakan taksonomi bloom direvisi Yoon, Vedd, \& Jones (2013) membagi kompetensi IFRS ke dalam 15 bagian (tabel 1). Pemberi kerja diminta memberikan pendapat mengenai pentingnya mahasiswa menguasai setiap bagian kompetensi IFRS apabila telah lulus. Sayangnya, penelitian tersebut tidak menyajikan apakah ekpektasi pemberi kerja secara signifikan berbeda untuk setiap kompentsi.

Untuk dapat menghasilkan lulusan akuntansi yang memiliki kompetensi IFRS, perguruan tinggi perlu mengintegrasikan IFRS ke dalam kurikulum. Chiang (2013) menemukan bahwa IFRS kurang terintegrasi ke dalamkurikulum akuntansi di Amerika Serikat. Selama ini, kurikulum akuntansi di Amerika Serikat sudah padat dan difokuskan pada US GAAP. 
Tabel 1: Kompetensi IFRS dengan Menggunakan Taksonomi Bloom Direvisi Sumber: Yoon, Vedd, \& Jones (2013)

\begin{tabular}{|l|l|c|}
\hline \multicolumn{1}{|c|}{ Tujuan pembelajaran mahasiswa } & $\begin{array}{c}\text { Kategori Taksonimi } \\
\text { Bloom direvisi }\end{array}$ & $\begin{array}{c}\text { Level } \\
\text { Taksonomi }\end{array}$ \\
\hline $\begin{array}{l}\text { Mendefinisikan istilah International Financial } \\
\text { Reporting Standard }\end{array}$ & Mengingat & 1 \\
\hline $\begin{array}{l}\text { Membandingkan persamaan dan perbedaan antara } \\
\text { IFRS dan US GAAP }\end{array}$ & Pemahaman \\
\hline $\begin{array}{l}\text { Membedakan antara antara principles-based dan } \\
\text { rules based }\end{array}$ & Pemahaman & 2 \\
\hline $\begin{array}{l}\text { Menjelaskan peranan International Accounting } \\
\text { Standard Board }\end{array}$ & Pemahaman & 2 \\
\hline $\begin{array}{l}\text { Menjelaskan perkembangan adopsi IFRS saat ini } \\
\text { Mendeskripsikan proses penetapan standar IFRS }\end{array}$ & Pemahaman & 2 \\
\hline $\begin{array}{l}\text { Membaca dan mengerti laporan keuangan berbasis } \\
\text { IFRS. }\end{array}$ & Aplikasi & 2 \\
\hline $\begin{array}{l}\text { Mengaplikasikan IFRS 1 (first-time adoption of } \\
\text { IFRS) kepada entitas }\end{array}$ & Aplikasi \\
\hline $\begin{array}{l}\text { Mengaplikasikan IFRS dalam pencatatan transaksi } \\
\text { bisnis }\end{array}$ & Aplikasi & 3 \\
\hline $\begin{array}{l}\text { Mengaplikasikan IFRS untuk entitas kecil dan } \\
\text { menengah (small and medium sized entities) }\end{array}$ & Aplikasi \\
\hline Membuat laporan keuangan berbasis IFRS & Aplikasi & 3 \\
\hline Menggunakan bahasa program XBRL untuk IFRS & Aplikasi & 3 \\
\hline Menganalisa laporan keuangan berbasis IFRS. & Analisa & 3 \\
\hline $\begin{array}{l}\text { Merekonsiliasi IFRS dengan laporan keuangan } \\
\text { berbasis US GAAP }\end{array}$ & Analisa \\
\hline $\begin{array}{l}\text { Melakukan penilaian (profesional judgement) untuk } \\
\text { mengevaluasi alternatif perlakuan } \\
\text { akuntansi sesuai dengan IFRS terhadap suatu } \\
\text { situasi/kejadian ekonomi. }\end{array}$ & Evaluasi & 4 \\
\hline
\end{tabular}

Kebanyakan mahasiswa mulai diperkenalkan pada IFRS pada mata kuliah akuntansi keuangan menengah. Penambahan materi IFRS ke dalam kurikulum dikhawatirkan akan menyebabkan penambahan jumlah kredit yang harus ditempuh mahasiswa selama perkuliahan.

Sugahara (2013) juga menemukan bahwa kebanyakan responden setuju bahwa adopsi IFRS meningkatkan pentingnya konvergensi pendidikan akuntansi secara global. Konvergensi pendidikan akuntansi secara global berarti bahwa ada keseregaman pendidikan akuntansi di di berbagai negara. Keberhasilan konvergensi pendidikan akuntansi secara global antara lain dipengaruhi oleh perbedaan budaya, bahasa, serta tingkat pengetahuan akan International Education Standard.

Coetzee \& Schmulian (2013) dan Carvalho \& Salotti (2013) menemukan bahwa ada dua hal utama yang menghambat mahasiswa di Afrika Selatan dan Brazil dalam mempelajari IFRS. Hambatan yang pertama adalah perbedaan bahasa. Coetze \& Schumulian (2013) menyatakan 
bahwa buku ajar dan materi IFRS lainnya tidak memakai bahasa lokal sehingga menuntut para pengajar akuntansi untuk menerje-mahkannya. Dampaknya adalah waktu para pengajar akuntansi untuk melakukan penelitian dan tugas-tugas lainnya sangat berkurang.

Di Brasil, bahasa pengantar yang dipakai di Brazil adalah Portugis sehingga beberapa institusi di Brazil telah menerjemahkan IFRS ke dalam bahasa lokal. Permasalahannya adalah meskipun kebanyakan standar IFRS sudah ditranslasi ke dalam bahasa lokal, yaitu Portugis, beberapa topik akuntansi tetap harus menggunakan bahasa Inggris, seperti kerugian penurunan nilai (impairment losses).

Faktor kedua yang menghambat mahasiswa dalam mempelajari IFRS adalah perbedaan antara pendekatan principles-based di dalam IFRS dengan rules-based pada standar yang lama. Sebagai contoh, selama ini penentuan besarnya depresiasi di Brasil lebih dipengaruhi oleh tujuan pengurangan pajak. (Carvalho \& Salotti, 2013). Hal ini tentu berbeda dengan IFRS yang menjelaskan bahwa penentuan depresiasi harus menggambarkan penggunaan masa manfaat aset tetap tersebut. Perubahan dari rules-based menjadi principles-based menuntut revisi silabus dan ujian pada pengajaran akuntansi di perkuliahan (Coetzee \& Schmulian, 2013

\begin{tabular}{l}
\multicolumn{1}{c}{$\begin{array}{l}\text { Berdasarkan } \\
\text { penelitian } \\
\text { sebelumnya, maka } \\
\text { mengembangkan } \\
\text { pertanyaan penelitian } \\
\text { berikut: }\end{array}$}
\end{tabular}

PP1: Bagaimanakah persepsi mahasiswa akuntansi terhadap pentingnya kompetensi IFRS dalam bekerja.

PP2: Bagaimanakah kompetensi mahasiswa dalam memahami IFRS? (Tabel 3)

PP3: Bagaimanakah kompetensi mahasiswa dalam mengaplikasikan IFRS pada laporan keuangan?

PP4: Bagaimanakah persepsi mahasiswa akuntansi mengenai integrasi IFRS ke dalam proses pembelajaran akuntansi keuangan?

PP5: Faktor-faktor apa sajakah yang dapat mendorong dan menghambat mahasiswa akuntansi dalam mempelajari IFRS selama di perkuliahan?

\section{Metode Penelitian}

Penelitian ini menggunakan kuesioner untuk pengumpulan data. Sampel penelitian merupakan mahasiswa akuntansi S1 di tiga perguruan tinggi swasta di Indonesia yang berlokasi di kota Jakarta, Tangerang Selatan, dan Bekasi. Mahasiswa akuntansi tersebut harus sedang atau sudah menempuh mata kuliah Akuntansi Keuangan Lanjutan. Akuntansi Keuangan Lanjutan adalah mata kuliah akuntansi keuangan terakhir yang mengajarkan mahasiswa pencatatan transaksi keuangan sampai dengan penyusunan laporan keuangan termasuk standar akuntansi keuangan. Dari 94 kuesioner yang disebarksn, hanya 81 kuesioner yang dapat dianalisa $(86,175 \%) . \quad 13$ responden tidak menjawab seluruh pertanyaan tertutup (closed questions). Tabel 2 menunjukkan informasi mengenai demografis responden. 
Tabel 2: Informasi Demografis Responden

\begin{tabular}{|c|c|c|c|c|}
\hline \multicolumn{2}{|c|}{ Demografis Responden } & $\begin{array}{c}\text { Jumlah } \\
\text { Responden }\end{array}$ & Persentase & Rata-Rata \\
\hline \multicolumn{2}{|l|}{ Total Responden } & 81 & & \\
\hline \multicolumn{2}{|l|}{ Usia } & & & 20,06 \\
\hline \multirow[t]{2}{*}{ Jenis Kelamin } & Pria & 22 & $27,2 \%$ & \\
\hline & Wanita & 53 & $65,4 \%$ & \\
\hline \multirow{3}{*}{$\begin{array}{l}\text { Perguruan Tinggi } \\
\text { yang berlokasi di: }\end{array}$} & Jakarta & 24 & $29,6 \%$ & \\
\hline & Bekasi & 40 & $49,4 \%$ & \\
\hline & $\begin{array}{l}\text { Tangerang } \\
\text { Selatan }\end{array}$ & 17 & $21,0 \%$ & \\
\hline \multirow{2}{*}{$\begin{array}{l}\text { Apakah sudah } \\
\text { /sedang } \\
\text { menempuh } \\
\text { Akuntansi } \\
\text { Keuangan } \\
\text { Lanjutan? }\end{array}$} & $\begin{array}{l}\text { Sudah } \\
\text { menempuh }\end{array}$ & 22 & $27,2 \%$ & \\
\hline & $\begin{array}{l}\text { Sedang } \\
\text { menempuh }\end{array}$ & 59 & $72,8 \%$ & \\
\hline \multirow[t]{4}{*}{ IPK } & $\geq 3,50$ & 10 & $12,3 \%$ & \\
\hline & $3,00 \leq x<3,50$ & 49 & $60,5 \%$ & \\
\hline & $2,00 \leq x<3,00$ & 21 & $25,9 \%$ & \\
\hline & $<2,00$ & 1 & $1,2 \%$ & \\
\hline
\end{tabular}

Kuesioner penelitian terdiri dari 4 bagian. Pada bagian pertama, responden diminta untuk menilai seberapa penting kompetensi IFRS dalam bekerja (PP1). Terdapat dua pertanyaan yang diajukan kepada responden. Pertanyaan pertama mengenai seberapa penting kemampuan membaca dan menyusun laporan keuangan berbasis IFRS diperlukan dalam berkarir sebagai akuntan di Indonesia. Sedangkan pertanyaan yang kedua mengenai pentingnya pemahaman akan IFRS dan kemampuan mengaplikasikan IFRS dalam laporan keuangan untuk dapat berkompetisi dengan akuntan dari negara-negara ASEAN lainnya pada saat dimulainya perdagangan bebas ASEAN di tahun 2013.

Selanjutnya, bagian yang kedua menanyakan persepsi responden mengenai kompetensi mereka akan
IFRS. Kompetensi mahasiswa menggunakan dikhususkan pada kompetensi dalam memahami dan mengaplikasikan IFRS (PP2 dan PP3). Pemahaman dan pengaplikasian menggunakan pertanyaan yang digunakan oleh Yoon, Vedd, \& Jones (2013) yang telah dimodifikasi dan didasarkan dengan pada tujuan pembelajaran sesuai dengan taksonomi bloom direvisi (lihat tabel 3).

Pada bagian yang ketiga, mahasiswa diminta memberikan pendapat mereka mengenai integrasi IFRS ke dalam proses pembelajaran akuntansi keuangan di perkuliahan (PP4). Integrasi IFRS ke dalam proses pembelajaran diukur dari apakah buku ajar mata kuliah akuntansi keuangan yang digunakan berbasis IFRS dan apakah dosen akuntansi keuangan telah Bagian ini juga menanyakan faktor apa saja yang dapat mendorong 
Persepsi mahasiswa terhadap IFRS dan kompetensi mahasiswa dalam memahami dan mengaplikasikan IFRS

dan menghambat mahasiswa dalam mempelajari IFRS (PP5). Bagian yang keempat menanyakan informasi umum tentang responden.

Tabel 3: Taksonomi Bloom Direvisi

Sumber: Yoon, Vedd, \& Jones (2013) yang telah disesuaikan

\begin{tabular}{|l|c|c|}
\hline \multicolumn{1}{|c|}{ Tujuan Pembelajaran Mahasiswa } & $\begin{array}{c}\text { Kategori } \\
\text { Taksonomi Bloom } \\
\text { yang Direvisi }\end{array}$ & $\begin{array}{c}\text { Level } \\
\text { Taksonomi }\end{array}$ \\
\hline $\begin{array}{l}\text { Mahasiswa mampu menjelaskan perbedaan } \\
\text { antara antara principles-based dan rules based. }\end{array}$ & Pemahaman & 2 \\
\hline $\begin{array}{l}\text { Mahasiswa mampu membandingkan persamaan } \\
\text { dan perbedaan antara IFRS dan PSAK berbasis } \\
\text { IFRS. }\end{array}$ & Pemahaman & 2 \\
\hline $\begin{array}{l}\text { Mahasiswa mampu menjelaskan perkembangan } \\
\text { konvergensi IFRS di Indonesia saat ini. }\end{array}$ & Pemahaman & 2 \\
\hline $\begin{array}{l}\text { Mahasiswa mampu menjelaskan proses } \\
\text { penetapan standar IFRS }\end{array}$ & Pemahaman & 2 \\
\hline $\begin{array}{l}\text { Mahasiswa mampu membaca dan mengerti } \\
\text { laporan keuangan berbasis IFRS. }\end{array}$ & Aplikasi & 3 \\
\hline $\begin{array}{l}\text { Mahasiswa mampu mencatat transaksi } \\
\text { keuangan sesuai dengan IFRS. }\end{array}$ & Aplikasi & 3 \\
\hline $\begin{array}{l}\text { Mahasiswa mampu membuat laporan keuangan } \\
\text { berbasis IFRS. }\end{array}$ & Aplikasi & 3 \\
\hline
\end{tabular}

\section{Hasil Penelitian}

Hasil Pengujian Validitas dan Reliabilitas Instrumen

Berdasarkan 75 kuesioner yang dianalis, hasil pengujian validitas dengan analisis faktor menunjukkan bahwa nilai KMO-MSA sebesar untuk persepsi mahasiswa terhadap pentingnya kompetensi IFRS dalam bekerja adalah sebesar 0,500, kompetensi mahasiswa dalam memahami IFRS sebesar sebesar 0,742 , kompetensi ma hasiswa dalam mengaplikasikan IFRS sebesar 0,730, dan persepsi mahasiswa mengenai integrasi IFRS ke dalam proses pembelajaran di perkuliahan sebesar 0,500. Nilai KMO-MSA telah memenuhi ambang batas yaitu 0,500. Dengan begitu, instrumen penelitian valid.

Hasil pengujian reliabilitas dengan menggunakan CronbachAlpha untuk persepsi mahasiswa terhadap pentingnya kompetensi IFRS dalam bekerja adalah sebesar 0,609, kompetensi mahasiswa dalam memahami IFRS sebesar sebesar 0,795 , kompetensi mahasiswa dalam mengaplikasikan IFRS sebesar 0,887, dan persepsi mahasiswa mengenai integrasi IFRS ke dalam proses pembelajaran di perkuliahan sebesar 0,713 . Seluruh hasil menunjukkan hasil Cronbach-Alpha $>0,6$ sehingga instrumen dapat dinyatakan reliable. 


\section{Analisis Mean Terhadap Respon Mahasiswa}

Tabel 4 menunjukkan hasil pengujian terhadap pertanyaan penelitian 1 sampai dengan 4. Rata-Rata persepsi mahasiswa terhadap pentingnya kompetensi IFRS dalam bekerja adalah 4,65 dengan nilai signifikansi 0,000 yang berarti bahwa memandang bahwa kompetensi IFRS penting di dalam bekerja. Akan tetapi, persepsi mahasiswa terhadap kompetensi mereka dalam memahami IFRS adalah 2,80 dengan signifikansi 0,007. Mahasiswa memandang bahwa mereka belum memiliki kompentensi pemahaman IFRS yang cukup. Mahasiswa juga memandang bahwa mereka hanya memiliki kompetensi yang cukup dalam mengaplikasikan IFRS ke dalam laporan keuangan.

Tabel 4

Hasil Pengujian dengan Menggunakan One Sample t-test Mean Analysis

\begin{tabular}{|c|c|c|c|c|c|c|}
\hline \multicolumn{2}{|r|}{ Pertanyaan Penelitian } & \multirow{2}{*}{$\begin{array}{l}N \\
81\end{array}$} & \multirow{2}{*}{$\begin{array}{l}\text { Mean } \\
4,65\end{array}$} & \multirow{2}{*}{$\begin{array}{r}\text { Std } \\
\text { Dev } \\
0,528\end{array}$} & \multirow{2}{*}{$\begin{array}{c}\begin{array}{c}\text { Sig. } \\
(2-\end{array} \\
\text { tailed)* }\end{array}$} & \multirow{2}{*}{$\begin{array}{c}\text { Nilai } \\
\text { Tengah } \\
\text { Kisaran } \\
\text { Teoritis } \\
4\end{array}$} \\
\hline 1 & $\begin{array}{l}\text { Persepsi mahasiswa akuntansi } \\
\text { terhadap pentingnya kompetensi }\end{array}$ & & & & & \\
\hline 2 & $\begin{array}{l}\text { IFRS dalam bekerja. } \\
\text { Kompetensi mahasiswa dalam } \\
\text { memahami IFRS }\end{array}$ & 81 & 2,80 & 0,641 & 0,007 & 3 \\
\hline 3 & $\begin{array}{l}\text { Kompetensi mahasiswa dalam } \\
\text { mengaplikasikan IFRS pada laporan } \\
\text { keuangan }\end{array}$ & 81 & 3,16 & 0,766 & 0,630 & 3 \\
\hline 4 & $\begin{array}{l}\text { Persepsi mahasiswa akuntansi } \\
\text { mengenai integrasi IFRS ke dalam } \\
\text { proses pembelajaran akuntansi } \\
\text { keuangan di perkuliahan? }\end{array}$ & 81 & 4,17 & 0,834 & 0,066 & 4 \\
\hline
\end{tabular}

* Signifikan pada $95 \%$ confidence level

Kompetensi mahasiswa dalam memahami dan mengaplikasikan IFRS tentu menimbulkan tantangan bagi perguruan tinggi mengingat bahwa rata-rata persepsi mahasiswa akuntansi mengenai integrasi IFRS ke dalam proses pembelajaran akuntansi keuangan di perkuliahan adalah adalah 4,17 dengan nilai signifikan 0,066 pada kisaran teoritis 4 . Dengan kata lain, mahasiswa setuju bahwa IFRS telah terintegrasi ke dalam mata kuliah akuntansi keuangan. Bahkan di salah satu perguruan tinggi di Bekasi yang menjadi sampel dalam penelitian ini, IFRS juga diajarkan pada mata kuliah Teori Akuntansi, Special Topics for Accounting, dan Auditing.

Untuk mengeksplorasi faktor apa sajakah yang mempengaruhi mahasiswa dalam mempelajari IFRS, maka mahasiswa diminta menyebutkan masing-masing dua hal utama yang menghambat dan mendorong mahasiswa dalam mempelajari IFRS di perkuliahan. Tabel 5 menunjukkan tiga faktor terbesar yang menghambat dan mendorong mahasiswa dalam mempelajari IFRS. Secara umum, mahasiswa berpendapat bahwa kemampuan dosen dalam menyampaikan IFRS dapat 
menghambat maupun mendorong mahasiswa dalam mempejari IFRS. Selain dosen, buku teks yang menggunakan bahasa Inggris dan kurangnya materi dalam mempelajari IFRS turut menjadi faktor penghambat.
Meski begitu, mahasiswa termotivasi mempelajari IFRS terutama karena IFRS merupakan standar yang berlaku di banyak negara dan tuntutan dunia kerja.

Tabel 5

Faktor Pendorong dan Penghambat dalam Mempelajari IFRS

\begin{tabular}{|c|l|c|}
\cline { 2 - 3 } & \multicolumn{1}{|c|}{ Faktor Penghambat dalam Mempelajari IFRS } & $\begin{array}{c}\text { Jumlah } \\
\text { Respon }\end{array}$ \\
\hline 1 & $\begin{array}{l}\text { Dosen yang kurang jelas dalam menyampaikan IFRS } \\
\text { serta tidak menggunakan IFRS sebagai acuan. }\end{array}$ & 45 \\
\hline 3 & $\begin{array}{l}\text { Kesulitan memahami Teksbook yang berbahasa } \\
\text { Inggris. } \\
\text { Sarana yang kurang untuk mempelajari IFRS, seperti } \\
\text { buku. }\end{array}$ & 17 \\
\hline & \multicolumn{2}{|c|}{ Faktor Pendorong dalam Mempelajari IFRS } \\
\hline 1 & $\begin{array}{l}\text { IFRS adalah standar yang diimplementasikan di } \\
\text { banyak negara, termasuk Indonesia } \\
\text { Dosen yang jelas dalam menyampaikan IFRS }\end{array}$ & $\begin{array}{c}\text { Jumlah } \\
\text { Respon }\end{array}$ \\
\hline 3 & $\begin{array}{l}\text { Tuntutan dalam pekerjaan } \\
23\end{array}$ \\
\cline { 2 - 3 }
\end{tabular}

\section{Kesimpulan, Keterbatasan, dan Rekomendasi Penelitian}

Hasil penelitian ini menunjukkan bahwa dunia pendidikan masih memiliki tantangan dalam meningkatkan kompetensi mahasiswa akan IFRS. Sekalipun mahasiswa memandang bahwa kompetensi IFRS penting diperlukan dalam dunia kerja dan IFRS yang sudah terintegrasi dalam mata kuliah akuntansi keuangan, mahasiswa masih berpandangan bahwa mereka belum memiliki kompetensi yang baik dalam memahami dan mengaplikasi IFRS.
Tenaga pendidik tetap dipandang menjadi salah satu faktor utama yang mempengaruhi mahasiswa dalam mempelajari IFRS. Disamping itu, kebutuhan akan buku teks yang berbahasa Indonesia dan materi IFRS yang diperbanyak di perkuliahan juga akan membantu mahasiswa.

Penelitian ini memiliki beberapa keterbatasan. Pertama, sampel yang digunakan dalam penelitian ini hanya berasal dari tiga perguruan tinggi sehingga diperlukan sampel yang lebih besar dengan agar dapat menganalisis kompetensi IFRS mahasiswa di 
Indonesia. Kedua, kompetensi mahasiswa akan IFRS hanya diukur pada tingkatan pemahaman dan pengaplikasian. Kompetensi juga dapat diukur sampai ke tingkat analisa dan evaluasi sebagaimana dijelaskan dalam tujuan pembelajaran Taksonomi Bloom Direvisi. Ketiga, penelitian ini tidak mencakup persepsi dosen di setiap universitas. Persepsi dosen akan kompetensi mahasiswa diperlukan karena mereka adalah pihak yang menguji kemampuan mahasiswa secara tertulis maupun lisan.

\section{Referensi}

ASEAN. 2009. ASEAN Mutual Recognition Arrangement Framework on Accountancy Services, diakses 5 November 2013,

<http://www.asean.org/communitie s/asean-economiccommunity/item/asean-mutualrecognition-arrangementframework-on-accountancyservices-3>.

ASEAN Federation Accountant. 2012. Annual Report 2012, diakses 5 November 2013, <http://www.aseanaccountants.org /downloads/resources/annualrepor t/AFA_Annual_Report_2012.pdf >.

Carvalho, L.N. \& Salotti, B.M. 2013. Adoption of IFRS in Brazil and the Consequences to Accounting Education, Issues in Accounting Education, vol.28 no.2, pp.235242.

Chiang, B. 2013. IFRS in the Accounting Curriculum Implications from Different Perspectives, International Business and Management, vol.6, no.2, pp.1-8.

Coetze, S.A. \& Schmulian, A. 2013. The Effect of IFRS Adoption on Financial Reporting Pedagogy in South Africa. Issues in Accounting Education. Vol. 28 no.2, pp.243251.

Ikatan Akuntan Indonesia 2008, Ikatan Akuntan Indonesia, diakses 1 November
$<$ http://www.iaiglobal.or.id/berita/d etail.php?id=19>.

Ikatan Akuntan Indonesia 2012 Ikatan Akuntan Indonesia, diakses 1 November 2013, $<$ http://www.iaiglobal.or.id/berita/d etail.php?id=373>.

Ikatan Akuntan Indonesia 2013a, Ikatan Akuntan Indonesia, diakses 1 November 2013, <http://www.iaiglobal.or.id/v02/aku ntan profesional.php>.

Ikatan Akuntan Indonesia 2013b, Ikatan Akuntan Indonesia, diakses 1 November 2013, <http://www.iaiglobal.or.id/v02/beri ta/detail.php?catid=\&id $=511>$.

International Monetary Fund. 2009. London Summit - Leaders' Statement 2 April 2009, diakses 5 November 2013, <http://www.imf.org/external/np/se c/pr/2009/pdf/g20_040209.pdf>.

James, M.L, Blaszczynski, C. 2010. Accounting Students' Perceptions of International Financial Reporting Standards, Journal for Global Business, vol. 10, no. 2, pp.37-49.

Kementerian Perdagangan. 2012. Menuju ASEAN Economic Community 2015, diakses 5 November 2013 $<$ http://ditjenkpi.kemendag.go.id/w ebsite kpi/Umum/Setditjen/Buku\% 20Menuju\%20ASEAN\%20ECONO MIC\%20COMMUNITY\%202015.p df $>$.

Republik Indonesia. 2011. UndangUndang No. 5 Tahun 2011 tentang Akuntan Publik. Sekretariat Negara, Jakarta.

Sugahara, S. 2013.Japanese Accounting Academics' Perceptions on the Global Convergence of Accounting Education in Japan, Asian Review of Accounting, vol. 21 no. 3, pp. 180-204.

Yoon, S.W., Vedd, R., \& Jones, C.G. 2013. IFRS Knowledge, Skills, and Abilities: A Follow-Up Study of Employer Expectations for Undergraduate Accounting Majors, Journal of Education for Business, Vol. 88 No. 6, pp.352-360. 